\title{
Microsimulation of Land Use
}

\author{
Rolf Moeckel*, Klaus Spiekermann**, Carsten Schürmann*, Michael Wegener** \\ *Institute of Spatial Planning (IRPUD), University of Dortmund \\ **Spiekermann\&Wegener, Urban and Regional Research (S\&W)
}

\begin{abstract}
The project ILUMASS (Integrated Land-Use Modelling and Transportation System Simulation) aims at embedding a microscopic dynamic simulation model of urban traffic flows into a comprehensive model system incorporating changes of land use, the resulting changes in transport demand, and the impacts of transport on the environment. The land-use component of ILUMASS will be based on the land-use parts of an existing urban simulation model, but is to be microscopic like the transport parts of ILUMASS. Microsimulation modules will include models of demographic development, household formation, firm lifecycles, residential and non-residential construction, labour mobility on the regional labour market and household mobility on the regional housing market. These modules will be closely linked with the models of daily activity patterns and travel and goods movements modelled in the transport parts of ILUMASS developed by other partners of the project team. The design of the land-use model takes into account that the collection of individual micro data (i.e. data which because of their micro location can be associated with individual buildings or small groups of buildings) or the retrieval of individual micro data from administrative registers for planning purposes is neither possible nor, for privacy reasons, desirable. The land-use model therefore works with synthetic micro data which can be retrieved from generally accessible aggregate data.
\end{abstract}

\section{Keywords}

Microsimulation, Land Use, Transport, Environment, Micro Data

International Journal of Urban Sciences 7(1), 2003, 14-31. 


\section{Introduction}

There is growing awareness that the way of life practised in the most affluent countries of the world is not sustainable. People in the richest countries consume significantly more energy and other resources per capita than people in the poorest regions and by the same margin generate more greenhouse gases, noxious emissions and waste. This imbalance is aggravating due to the faster growth in income in the already richer regions and the subsequent changes in lifestyles, consumption, and travel patterns.

The causes of growing energy consumption and pollution by transport have a distinct spatial and urban dimension. With growing affluence and continuing low transport costs, urban residents choose more distant housing locations at the periphery of metropolitan areas to take advantage of better quality of life and lower land prices. Retail and service facilities and later workplaces in general follow and settle on greenfield sites with the effect that the proportion of car trips continues to grow at the expense of environment-friendly transport modes and that ever more open space is used for development.

All cities in Europe struggle with the problems of urban sprawl, yet mostly with little success. It is increasingly becoming clear that market forces will continue to lead to ever more dispersed, energy-wasteful urban settlement patterns. Land-use policies like the promotion of higher-density, mixed-use urban forms more suitable for public transport become necessary. But only a combination of land-use policies and transport policies promoting public transport and containing the private automobile can limit further urban dispersion and free metropolitan areas from their increasing auto-dependency. However, the necessary integration of land-use and transport planning is rarely achieved, and the complex interaction between land-use and transport policies is still poorly understood. Today there is a new interest in integrated models of urban land use and transport provoked by the environmental debate. In the United States and in Europe the number of integrated urban land-use transport models that can be used for assessing environmental impacts of land-use and transport policies is increasing (Wegener 1994, 1998; United States Environmental Protection Agency 2000).

The project ILUMASS described in this paper is part of this development. ILUMASS (Integrated Land-Use Modelling And Transportation System Simulation) aims at embedding an existing microscopic dynamic simulation model of urban road traffic flows into a comprehensive model system incorporating both changes in land use and the resulting changes in transport demand. The project, which is funded by the German Federal Ministry of Education and Research, is a group project of institutes of the universities of Aachen, Bamberg, Dortmund, Cologne, and Wuppertal under the co-ordination of the Transport Research Institute of DLR, the German Aerospace Center. Study region for tests and first applications of the model is the urban region of Dortmund. The common database is being compiled in co-operation with the City of Dortmund. After its completion the integrated model is to be used for assessing the impacts of potential transport and land-use policies for the new land-use plan and transport master plan of the city.

The paper is organised in eight sections. After the introduction an overview of the ILUMASS project is given. Next the advantages of microsimulation and the needed micro database are discussed. Sections 5 to 7 show examples of microsimulation modules and their integration in the ILUMASS model. Finally the future of land-use/transport/environment models is discussed. 


\section{Overview of the ILUMASS Project}

The ILUMASS project aims at developing, testing, and applying a new type of integrated urban land-use/transport/environment (LTE) planning model. Urban LTE models simulate the interaction between urban land-use development, transport demand, traffic, and environment (Figure 1). The distribution of land uses in the urban region, such as residences, workplaces, shops, and leisure facilities, creates demand for spatial interaction, such as work, shopping, or leisure trips. These trips occur as road, rail, bicycle, or walking trips over the transport network in the region, and they have environmental impacts. There are two important kinds of feedback: The accessibility provided to locations in the region by the transport system influences the location decisions of developers, firms and households. Firms and households also take environmental factors such as clean air and absence of traffic noise in location decisions into account.

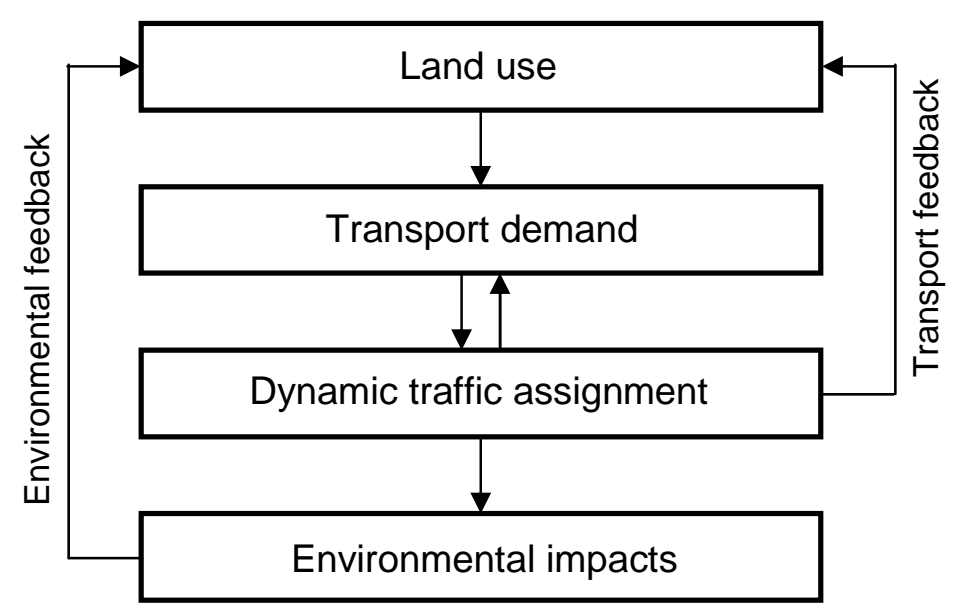

Figure 1 Feedbacks in LTE models

The land-use component of ILUMASS is developed based on the land-use parts of the mostly aggregate land-use transport model developed at IRPUD (Wegener 1999). However, the ILUMASS model is microscopic, i.e. all land-use changes and traffic flows will be modelled by microsimulation. The interactions between activity and mobility patterns are modelled at the level of individuals. New lifestyles and work patterns such as part-time work, telework, and teleshopping can be represented. The interactions between travel demand, car ownership, and residential and firm location as well as the interactions between land use, built form, and mobility behaviour are simulated. Furthermore the environmental impacts of transport such as traffic noise and exposure to air pollution are included. After its completion the integrated model is to be used for assessing the impacts of potential transport and land-use policies for the new land-use plan and transport master plan of the city of Dortmund.

The study region for tests and first applications of the model is the urban region of Dortmund (Figure 2). The area consists of the city of Dortmund and its 25 surrounding municipalities. The area is subdivided into 246 zones. However, the spatial resolution of 246 zones is not sufficient for microsimulation of transport, land use, and environmental impacts such as air quality or traffic noise. These types of models require a much higher spatial resolution. Therefore, raster cells of 100 by $100 \mathrm{~m}$ in size are introduced in the modelling system and used as addresses for activities. In order to bridge the data gap between zones and raster cells, GIS-based techniques are used to disaggregate zonal data to raster cells. Figure 3 is a detailed map of the city centre of Dortmund (the small square in the centre of Figure 2) showing the built-up area, the zone boundaries and the raster cells. In total, about 207,000 raster cells cover the study area. 


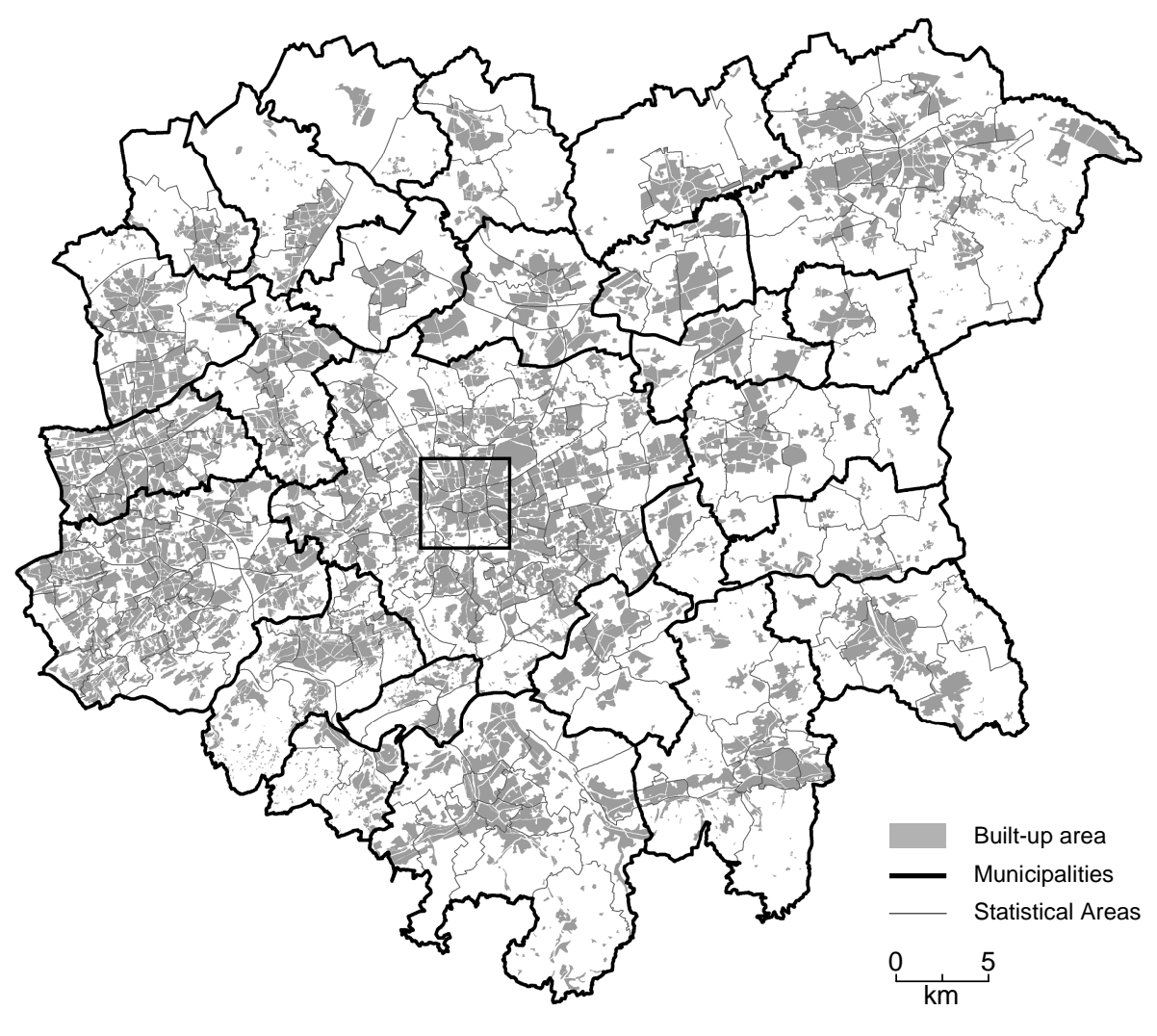

Figure 2 The study region of Dortmund and its 25 surrounding communities
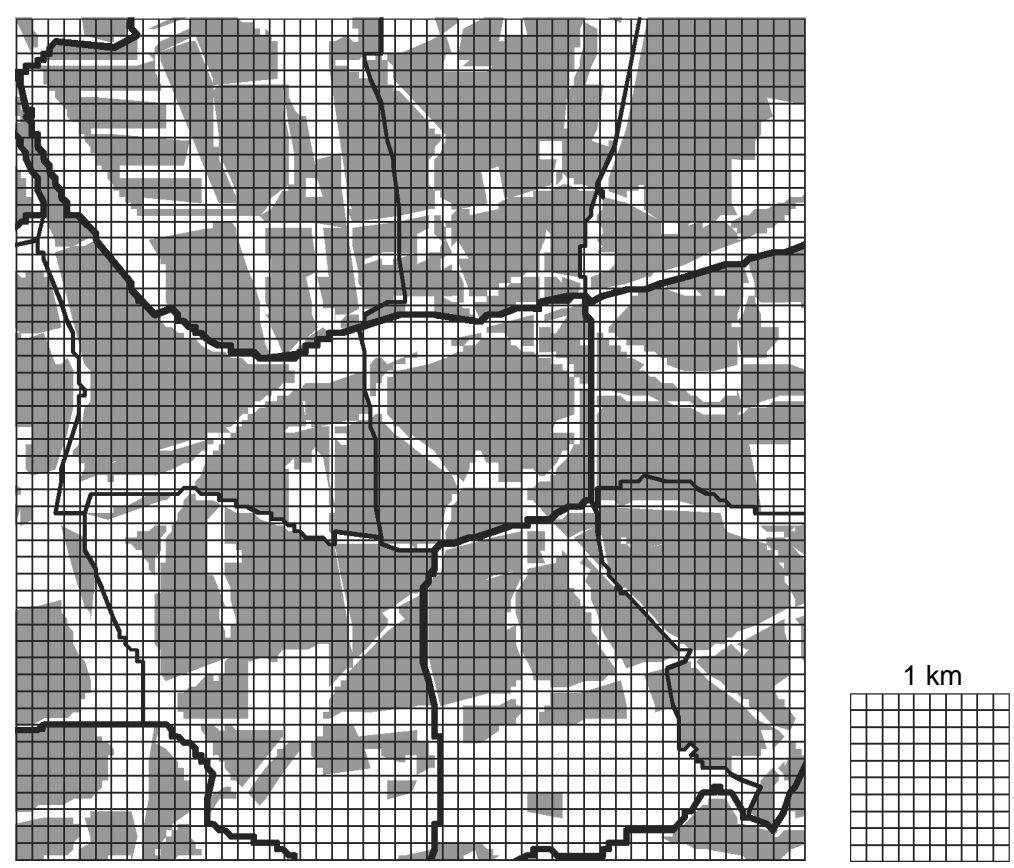

Figure 3 The Dortmund city centre with raster cells 


\section{Microsimulation}

The interest in sustainability, together with new technological developments and new planning policies, presents new challenges to urban modelling. New intermodal travel alternatives such as park-and-ride and kiss-and-ride, new forms of paratransit such as car-sharing, shared taxis or busses on demand and new lifestyles and work patterns such as part-time work, telework and teleshopping cannot be modelled by traditional aggregate four-step travel models. New activity-based travel models addressing these issues require more detailed information on household demographics and employment characteristics. New neighbourhood-scale planning policies to promote the use of public transport, walking and cycling require more detailed information on the precise location of activities. New concepts of intermodal urban goods transport ('city logistics') require detailed knowledge on the location of local shippers and recipients. In addition the models need to be able to predict not only economic but also environmental impacts of land use and transport policies, and this requires small-area forecasts of emissions from stationary and mobile sources as well as of immissions in terms of exposed population. The environmental impacts on the behaviour of households, businesses and public actors have to be modelled as feedback.

Existing urban models are too aggregate to respond to these challenges. Typical models distinguish only few industries, socio-economic groups and dwelling categories, too few to take account of new production and distribution technologies and emerging lifestyles and work patterns. Moreover, most urban models get their spatial dimension through a zonal system in which it is assumed that all attributes are uniformly distributed throughout a zone. Spatial interaction between zones is established via networks linked only to the centroids of the zones. Zone-based spatial models do not take account of topological relationships and ignore that socio-economic activities and their environmental impacts are continuous in space.

These considerations suggest a fundamentally new organisation of urban models based on a microscopic view of urban change. The method for this new type of model is Monte Carlo microsimulation. Basically, microsimulation is the reproduction of a macro process (e.g. suburbanisation) by many micro (e.g. moves of households) processes. These models aim at reproducing human behaviour at the individual level, i.e. how individuals choose between options following their perceptions, preferences and habits subject to constraints, such as uncertainty, lack of information and limits in disposable time and money. No deterministic assertions that are valid with certainty can be made. Instead probabilistic assertions that are valid only with probability are made about events.

Microsimulation was first used in social-science applications in the 1960s, yet applications in a spatial context remained occasional experiments without deeper impact though covering a wide range of phenomena such as spatial diffusion, urban development, transport behaviour, demographic and household dynamics and housing choice. Only recently microsimulation has found new interest because of its flexibility to model processes that cannot be modelled in the aggregate. Today there are several microsimulation models of urban land use and transport under development in North America: the California Urban Futures (CUF) Model at the University of California at Berkeley (Landis and Zhang 1998a, 1998b), the Integrated Land Use, Transport and Environment (ILUTE) model at Canadian universities (Miller 2001), the Urban Simulation (UrbanSim) model at the University of Washington, Seattle (Waddell 2000), and the 'second-generation' model of the Transport and Land Use Model Integration Program (TLUMIP) of the State of Oregon, USA. There are no efforts of comparable size in Europe. There are a few national projects, such as the Learning-Based Transportation Oriented Simulations System (ALBATROSS) of Dutch universities (Arentze and Timmermans 2000) or the Integrated Land-Use Modelling and Transportation System Simulation (ILUMASS) in Germany described here. 
Three kinds of process can be distinguished in microsimulation (Wegener et al. 1986):

- Choices. A choice stands for a selection between alternatives. A typical choice represents for instance the behaviour of a household looking for a dwelling in the housing market. Its propensity to move depends on its satisfaction with its present dwelling. It first chooses a neighbourhood in which to look for a dwelling, and this depends on its present residence and workplace. The household then looks for a dwelling in that neighbourhood guided by the attractiveness and price of vacant dwellings there. The household accepts a dwelling if it can significantly improve its housing condition. If it declines, it enters another search phase.

- Transitions. A transition represents a change from one state to another. A typical transition for instance is the evolution of a household during a certain time interval during which it is promoted to another household category with respect to nationality, age, income or size conditional on the relevant probabilities for events such as migration, birth of child, ageing/death, marriage or divorce, or the development of a firm from establishment through growth, decline to closure. Choice-based events such as marriage or divorce may be treated as transitions if the causal chain behind them is of no interest for the purpose of the model.

- Policies. Choices in which the decision maker is a public authority represent decisions by which the public authority intervenes as investor in the process of urban development. Policies usually are set by the user of the model in order to run different scenarios.

One of the important underlying behavioural theories are the binomial and the multinomial logit model (Domencich and McFadden 1975). The binomial logit model represents a decision between two alternatives. It generates an S-shaped distribution of probabilities giving a higher likelihood to more attractive alternatives. The S-shaped curve is theoretically well-founded to represent decisions of individuals. A multinomial logit model serves to simulate choices between several options; with increasing attractiveness the probability to select this alternative increases exponentially. Logit models represent decisions that are taken under uncertainty and limited information. Decisions are not modelled as utility maximisation but as systematic deviations from the optimum. For instance, the binomial logit model is applied to simulate whether a household decides to move or not. If the household has decided to move, a multinomial logit model is used to provide choice probabilities for different dwellings available on the housing market.

\subsection{Micro Database}

The collection of individual micro data, i.e. data that can be associated with single buildings, or the retrieval of individual micro data from administrative registers in most countries is neither allowed nor desirable for privacy reasons. Therefore the model works with synthetic micro data which can be retrieved from general accessible aggregate data. Results of the model will be published only in aggregated form. To observe this restriction, aggregate socio-economic data are disaggregated by biproportional and multiproportional procedures, such as iterative proportional fitting. By means of digital land-use plots, micro locations are determined. The synthetic micro data are statistically consistent with the aggregate input data.

The synthetic population represents individual actors in the form of households and household members. Each household has certain characteristics such as size, income, number of cars, and address. In addition, each person is represented by characteristics such as age, sex, nationality, and employment. These agents are assigned activities they accomplish during a day. They go to work, attend school, shop or see the doctor. They choose a transport mode and so generate traffic. In the long run, households may decide to move and so affect land use. 
The synthetic businesses represent the employers in the model. Businesses are described by their industry, number of employees, number of vehicles, and location in the study region. Public facilities are special cases of businesses. They include institutions like kindergartens, schools, universities or museums. Businesses affect land use by their establishment, relocation, or closure and transport by the person and goods movements they generate.

The micro database contains residential buildings and floorspace of non-residential buildings. Features associated with each dwelling are building type, size, quality, tenure and price. Every dwelling has a raster cell as a micro location. The non-residential floorspace distinguishes between industrial, retail, office, and public use. Raster cells are used as addresses for the microsimulation.

For the disaggregation of zonal activities to raster cells, GIS-based techniques are used. To disaggregate spatially aggregate data within a zone, the land-use distribution within that zone is taken into account, i.e. it is assumed that there are areas of different density in the zone. The spatial disaggregation of zonal data consists of three steps: the generation of a raster representation of land use, the assignment of probabilities to land-use categories and the allocation of the data to raster cells. Figure 4 illustrates the three steps for a simple example (Spiekermann and Wegener 1999, 2000).

- First, land-use data and zone borders, in vector based GIS usually stored as polygons, are converted to raster representation by using a point-in-polygon algorithm for the centroids of the raster cells. As a result each cell has two attributes, the land-use category and the zone number of its centroid. These cells represent the addresses for the disaggregation of zonal activity data.
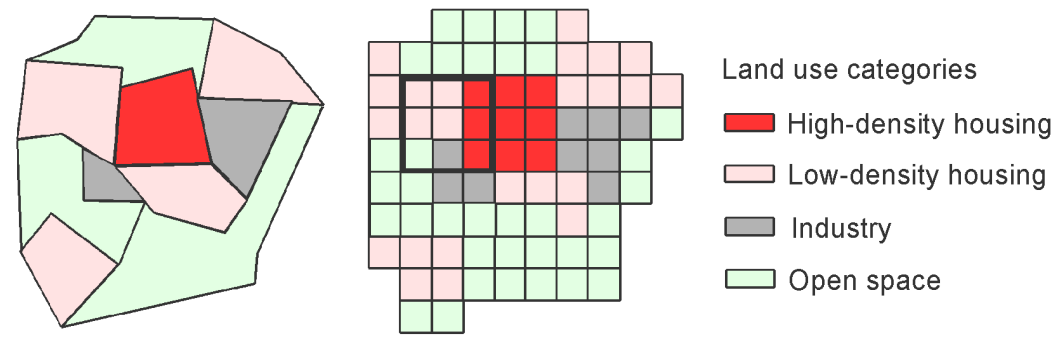

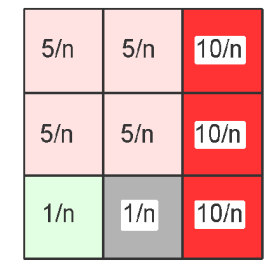

Probabilities

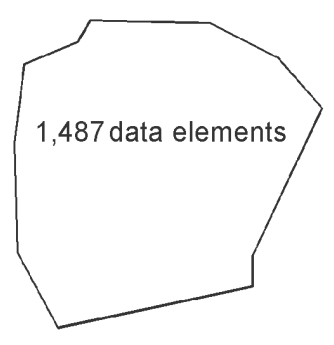

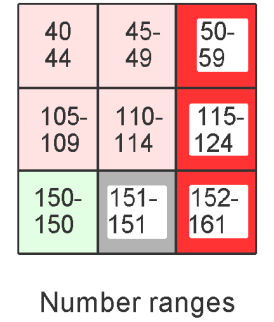

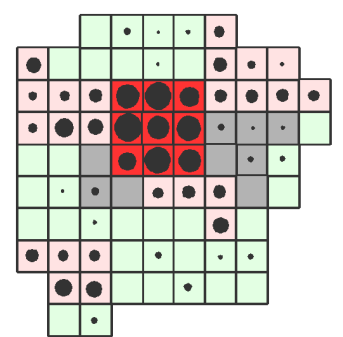

Weights

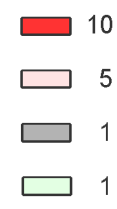

n Total weight of zone

100

(2) 50 data elements

10

Figure 4 Disaggregation of zonal data to raster data (Spiekermann and Wegener 2000: 48) 
- For each activity to be disaggregated weights are assigned to each land-use category, and all cells are attributed with the weights of their land-use category. Dividing the weight of a cell by the total of the weights of all cells of the zone gives the probability that that cell is the address of one element of the zonal activity. Cumulating the weights over the cells of a zone yields the range of numbers associated with each cell.

- Using a random number generator for each element of the zonal activity, one cell is selected as its address. The results are individual addresses for all activities and so a raster representation of the distribution of the activity within the zone.

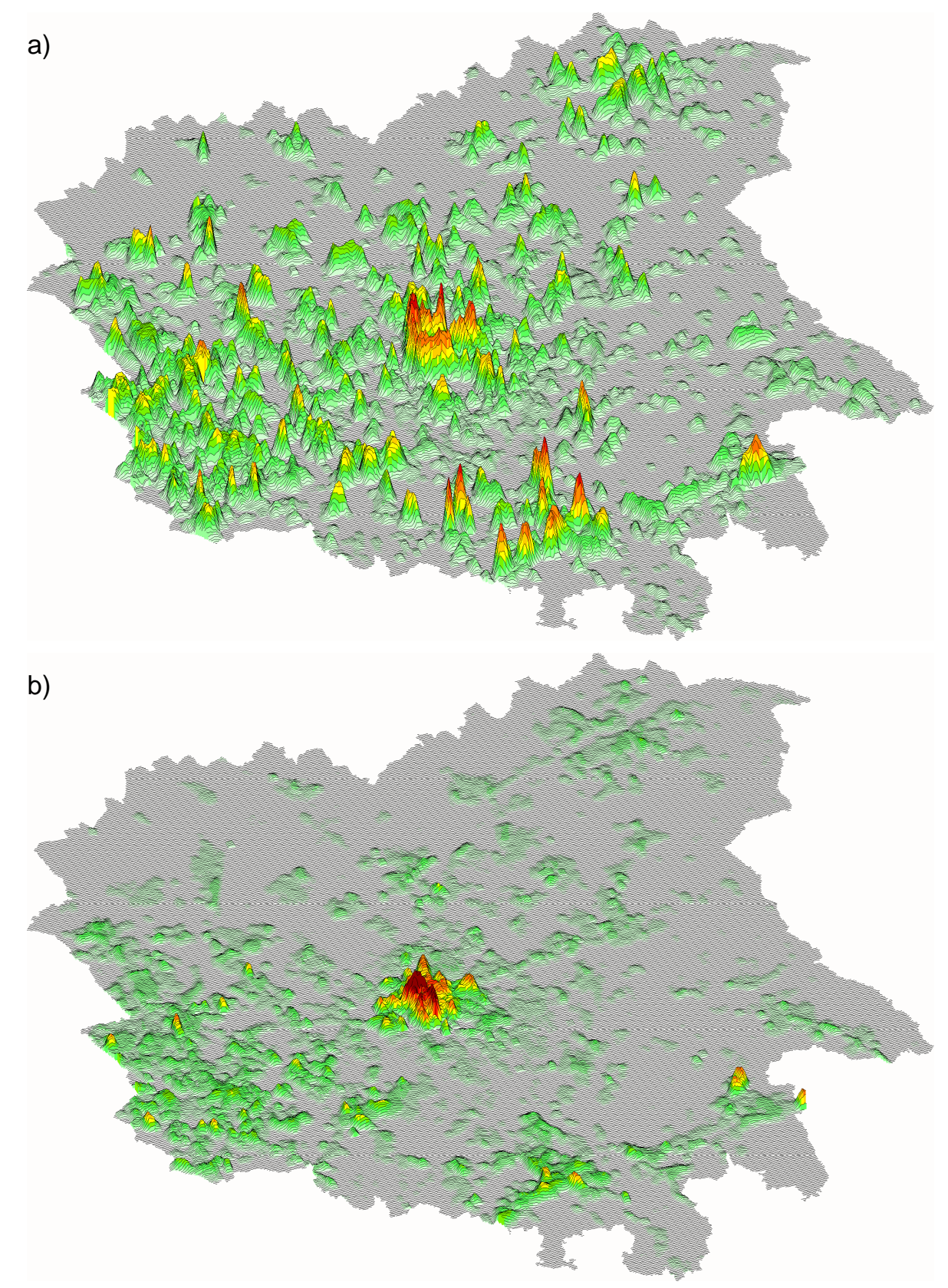

Figure 5 Three-dimensional representation of (a) residences and (b) workplaces 
Figure 5 visualises the disaggregate database of the study area as 3D surface: The surface (a) shows the spatial distribution of residences; in the centre one can see the low-density downtown and the high-density ring around the CBD in Dortmund. Other city centres of the surrounding cities can be observed. The surface (b) shows the distribution of workplaces; compared with the residences, workplaces are much more centralised in the city centre and in the sub-centres of the polycentric suburban area.

\subsection{Microsimulation Modules}

Microsimulation modelling consists of the selection of microsimulation modules, the definition of the data organisation and data interfaces, and the definition of output indicators. A microsimulation module is a programme unit that executes one elementary process (a choice, a transition, or a policy) and stores the result in the common micro database. It is always possible to include further microsimulation modules. Co-ordination between the modules is facilitated by a co-ordinator or scheduler programme. Each microsimulation module has defined input and output interfaces. A list of microsimulation modules used in ILUMASS ordered by increasing speed of change from slow to fast is presented in Figure 6:

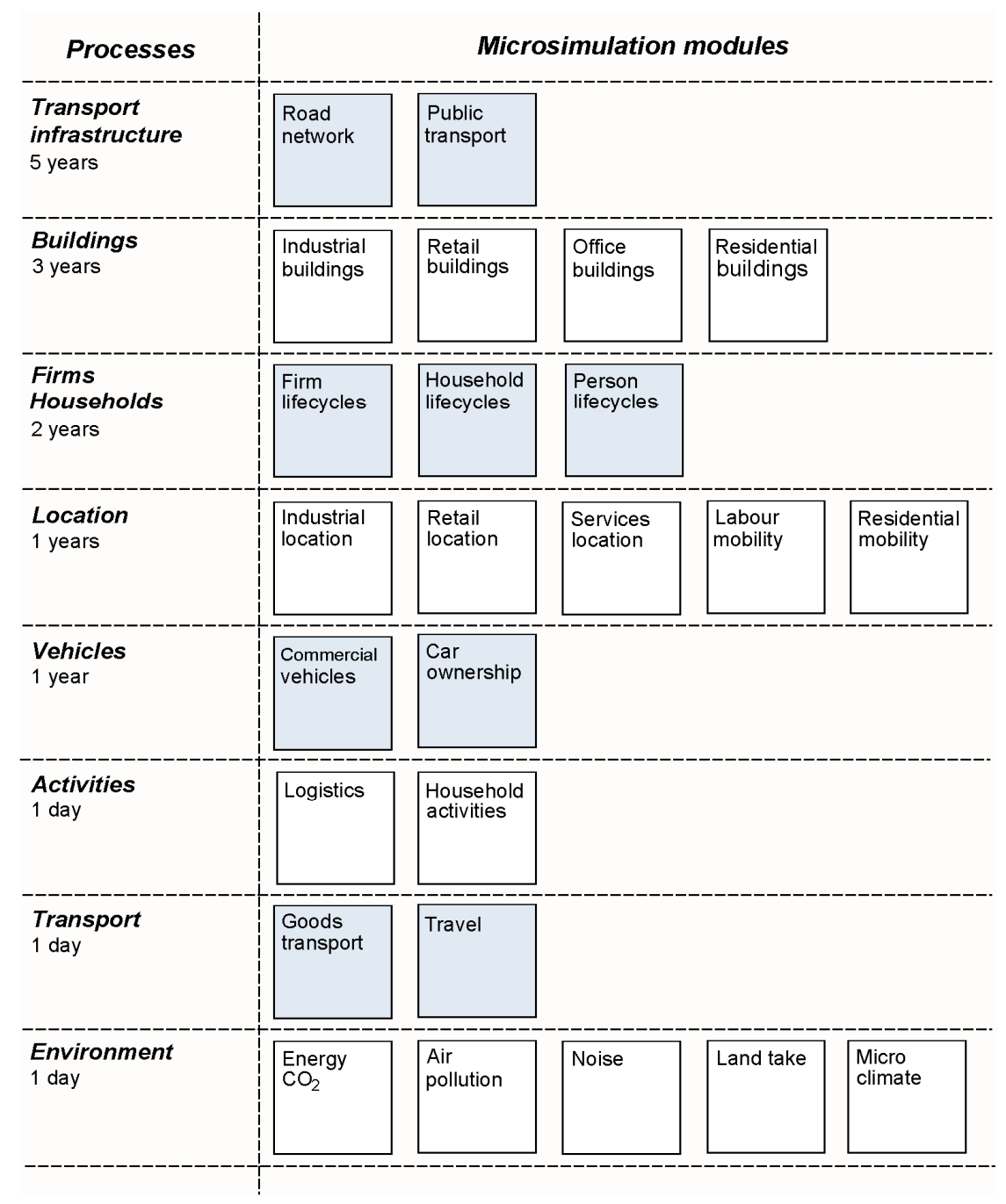

Figure 6 Urban change processes and microsimulation modules 
Transport infrastructure and buildings represent the slowest kind of change; their construction takes many years, and their lifecycle is counted in decades. Firms and households have also lifecycles of several years but are easier established or dissolved. Firms and households change their location several times during their life, yet even more frequently adjust their vehicle fleets to changing needs. Whereas all these changes are counted in years, logistics and household activities change from hour to hour during a single day. The fastest urban processes are goods transport and travel. They adjust in response to events in a matter of minutes. Environmental processes partly reflect the effects of human activities without delay but some have long-term consequences.

The microsimulation modules of ILUMASS interact in various ways with each other. Figure 7 shows that the number of interactions between the microsimulation modules is enormous (and would be even larger if also indirect impacts were taken into account).

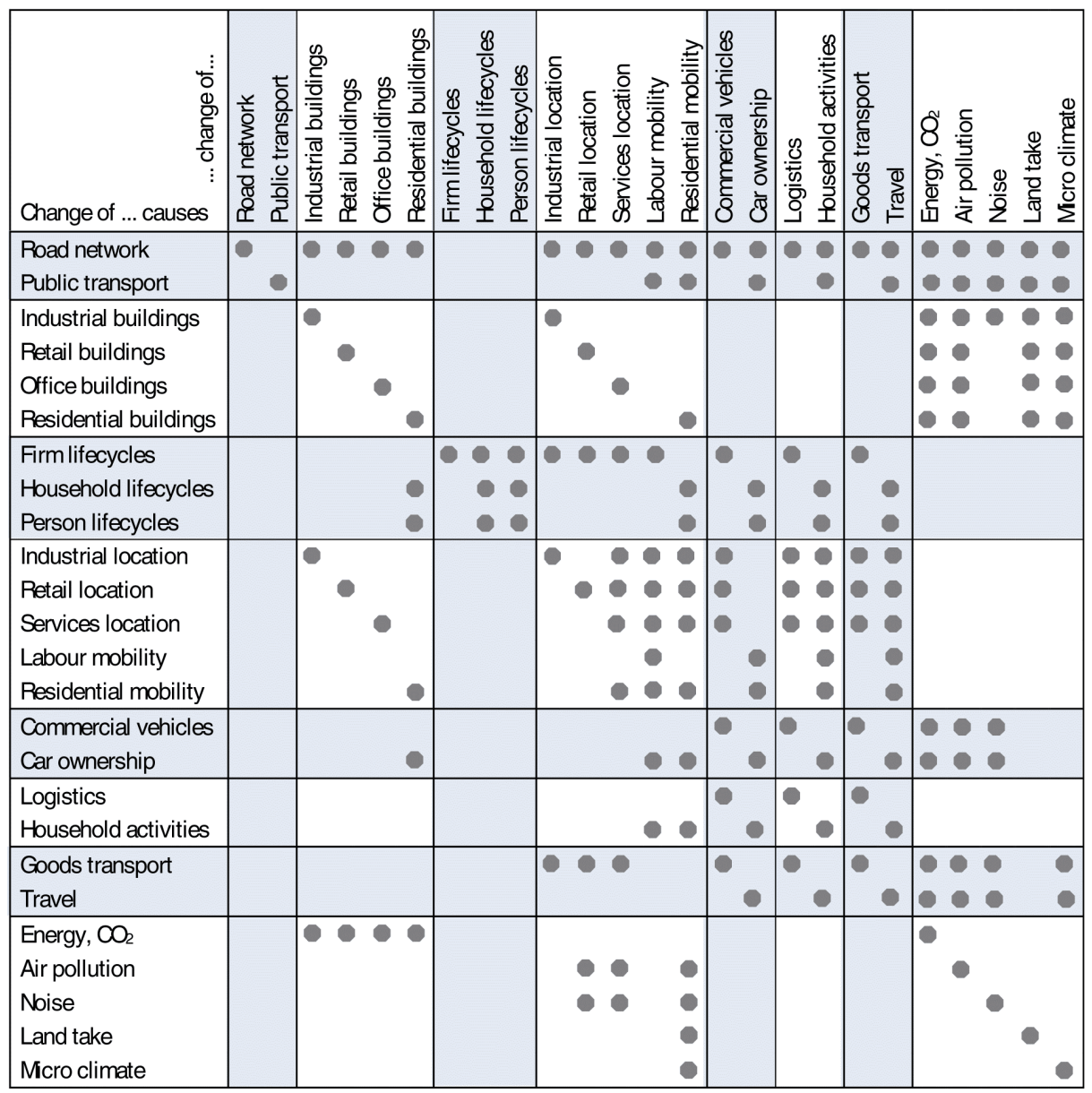

Figure 7 Interactions between microsimulation modules

Some of these interactions are highly delayed, i.e. take their time to work their way through the system. For instance, increasing demand for office space or housing will result in new office space or new housing only after several years because of long planning and construction periods. Other impacts are much faster. For instance, dwellings vacated by households enter the supply of available housing after a few weeks. Still other impacts are almost immediate, such as driver response to congestion. This variety of response speeds requires that the exchange of information between the microsimulation modules is very efficient. This is achieved by the common micro database. 


\section{Two Examples}

The following examples implemented in ILUMASS explain two microsimulation modules, household formation and housing choice.

\subsection{Household Formation}

The household formation microsimulation module models the evolution of household attributes associating each household with a particular life style (Figure 8). In the household formation module the following household events are modelled simultaneously for households and household members: birth, ageing, death; new household, dissolution of household; marriage/divorce, cohabitation/separation, separation of child, person joins household; new job, retirement, unemployment; change of income.

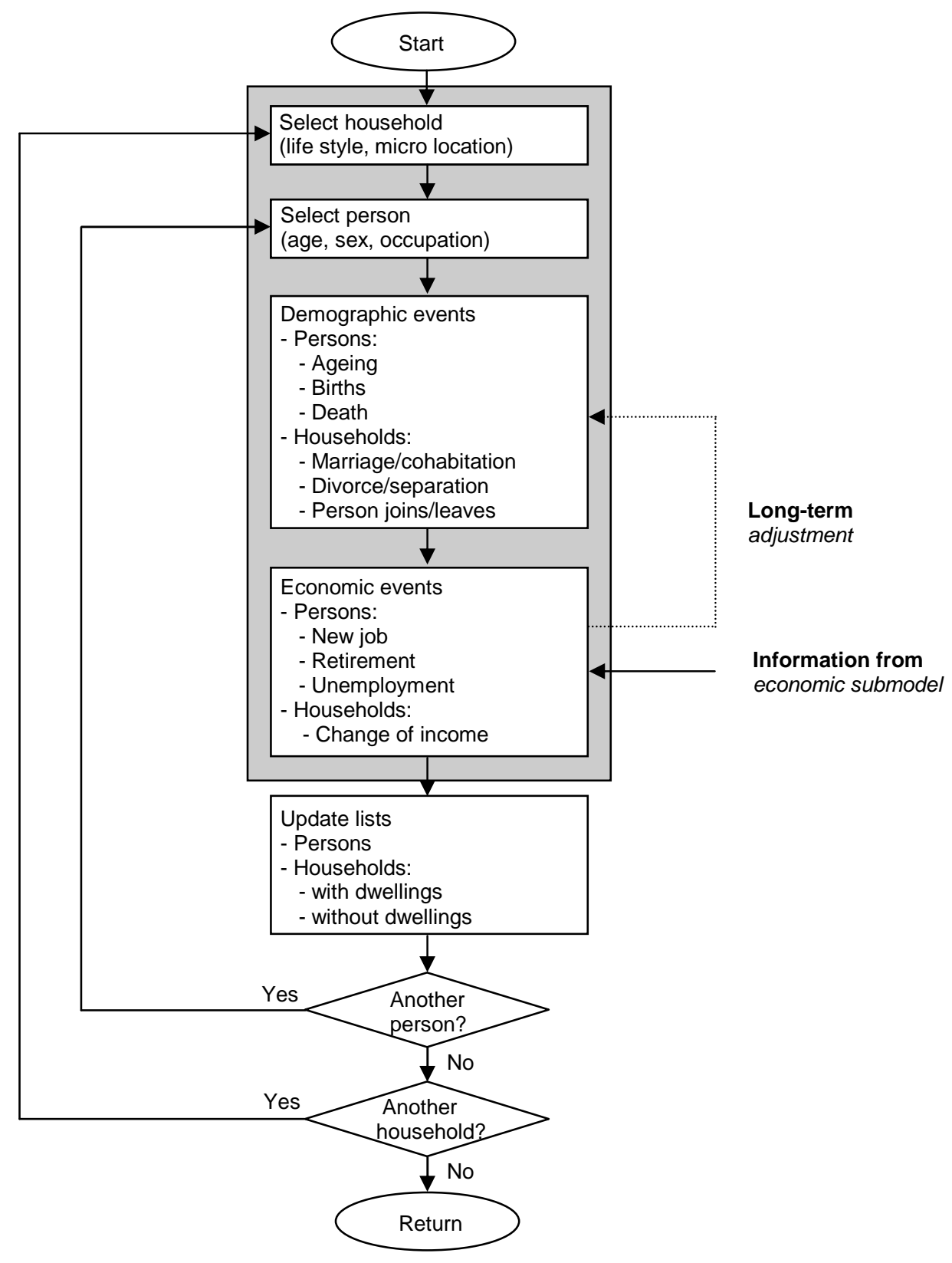

Figure 8 Microsimulation of household formation 
Even though household formation events in reality are the outcome of more or less rational decisions, most of them will not be modelled as decisions but simply as the result of the passage of time, i.e. as transitions (compare Section 3). Typical transitions are changes of the state of a household with respect to age or size conditional on the relevant probabilities for events such as ageing/death, birth of child, relative joins or leaves household. Also clearly choice-based events such as marriage or divorce are modelled as transitions because the causal chain behind them is not represented in the model. Some events result in the dissolution of households or the creation of new households. Other events, such as a new job or unemployment are triggered by external events such as hiring or firing in the labour market (represented in another part of the model not described here). Change of income is a consequence of employment-related events.

Beyond these straightforward relationships there is wide scope in the model for introducing more complex interdependencies between household and economic events. For instance, the rise of dual-worker households may be in part a life style choice and in part a necessity dictated by rising housing costs and stagnant real incomes. Children may delay new household formation or marriage. Childbearing may be postponed based on some combination of life style preferences and response to housing cost and income expectations. The role of labour market expectations in shaping these choices is an area of considerable policy implication.

\subsection{Housing Choice}

The housing choice microsimulation module models location and housing decisions of households who move into the region (immigration), move out of the region (outmigration), move into a dwelling for the first time (starter households), or have a dwelling and move into another dwelling (moves).

Dwellings are affected by ageing and by decisions on new construction, upgrading, and demolition modelled in other modules not described in this context. The housing choice model is a Monte Carlo microsimulation of transactions in the housing market. A market transaction is any successfully completed operation by which a household moves into or out of a dwelling or both.

There are two types of actors in the housing market (Figure 9): households looking for a dwelling ('dwelling wanted') and landlords looking for tenants or buyers ('dwelling for rent or sale'). The household looking for a dwelling behaves as a satisficer, i.e. it accepts a dwelling if this will improve its housing situation by a considerable margin. Otherwise, it enters another search phase, but after a number of unsuccessful attempts it abandons the idea of a move. The amount of improvement necessary to make a household move is assumed to depend on its prior search experience, i.e. to go up with each successful and down with each unsuccessful search. In other words, households adapt their aspiration levels to supply conditions on the market.

The attractiveness of a dwelling for a household is a weighted aggregate of the attractiveness of its location, its quality and its rent or price in relation to the household's housing budget. The attractiveness of the location and the quality of the dwelling are themselves multiattribute encompassing relevant attributes of the neighbourhood and of the dwelling 

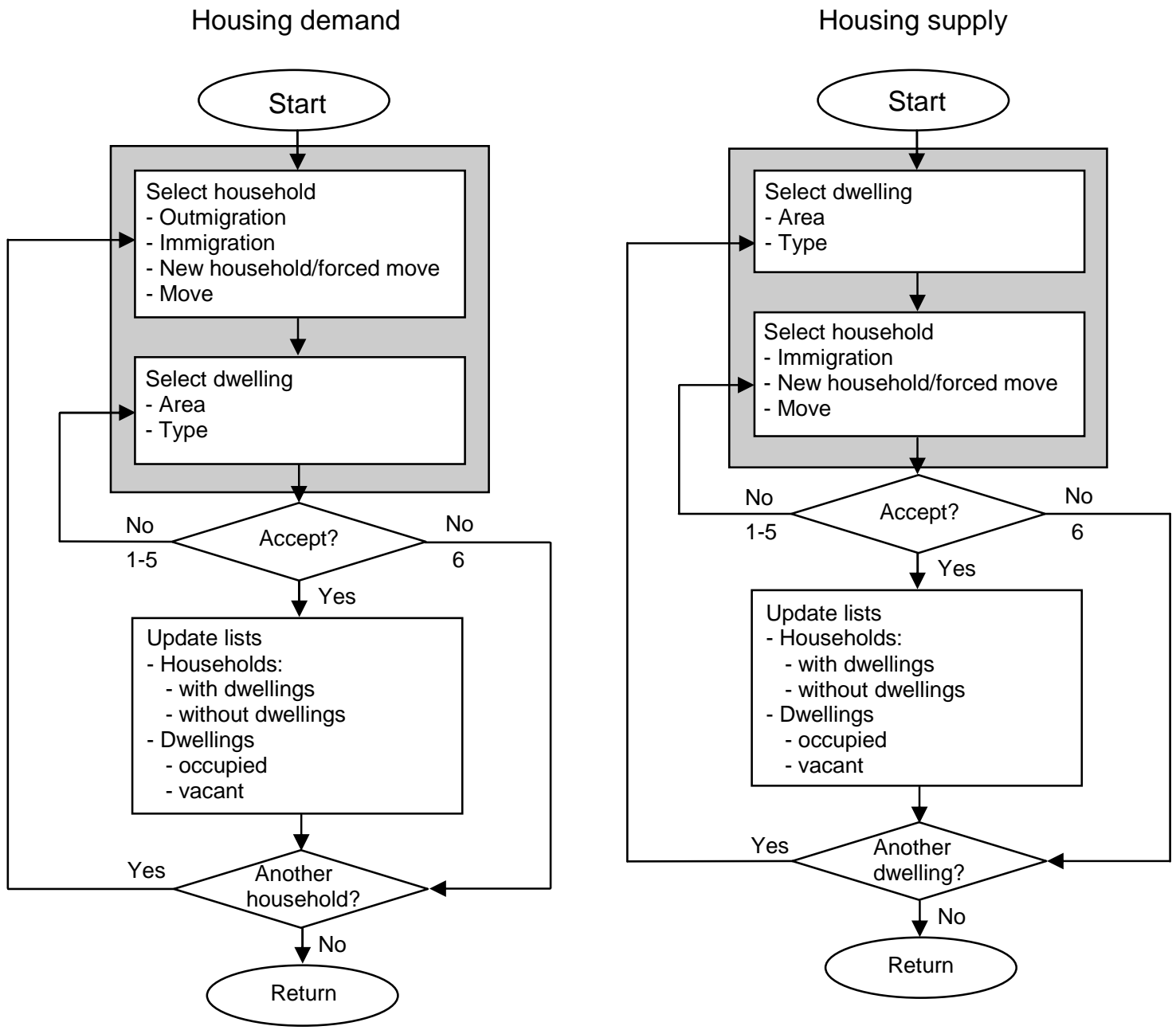

Figure 9 Microsimulation of housing choice

\section{Integration of the Land Use Modules in ILUMASS}

Figure 10 shows the relationship between the microsimulation of land use and the other parts of the ILUMASS model. Major inputs data are the synthetic 'populations' of housing, households, industrial and commercial buildings, firms and vehicles year as well as the road and public transport networks in the base.

These inputs are processed in the microsimulation modules of Figure 6: Households and household members, firms and workers, cars and commercial vehicles, and residential and non-residential buildings are aged by one simulation period and undergo all the changes indicated in Figure 7 (by choices, transitions, or policies) occurring during the simulation period.

For each forecasting year, the distributions of households, persons, firms, and workers are passed to the microsimulation modules forecasting travel and freight transport demand and dynamic traffic assignment. The traffic flows, link loads, and travel times and costs so generated are fed back to the land-use model in which they, through accessibility, affect the behaviour of developers, households, and firms (transport feedback). In addition they serve as input to the environmental modules, which calculate the resulting environmental impacts, such as air pollution and traffic noise. These in turn are fed back to the land-use models and affect the location decisions of developers, households, and firms (environmental feedback). 


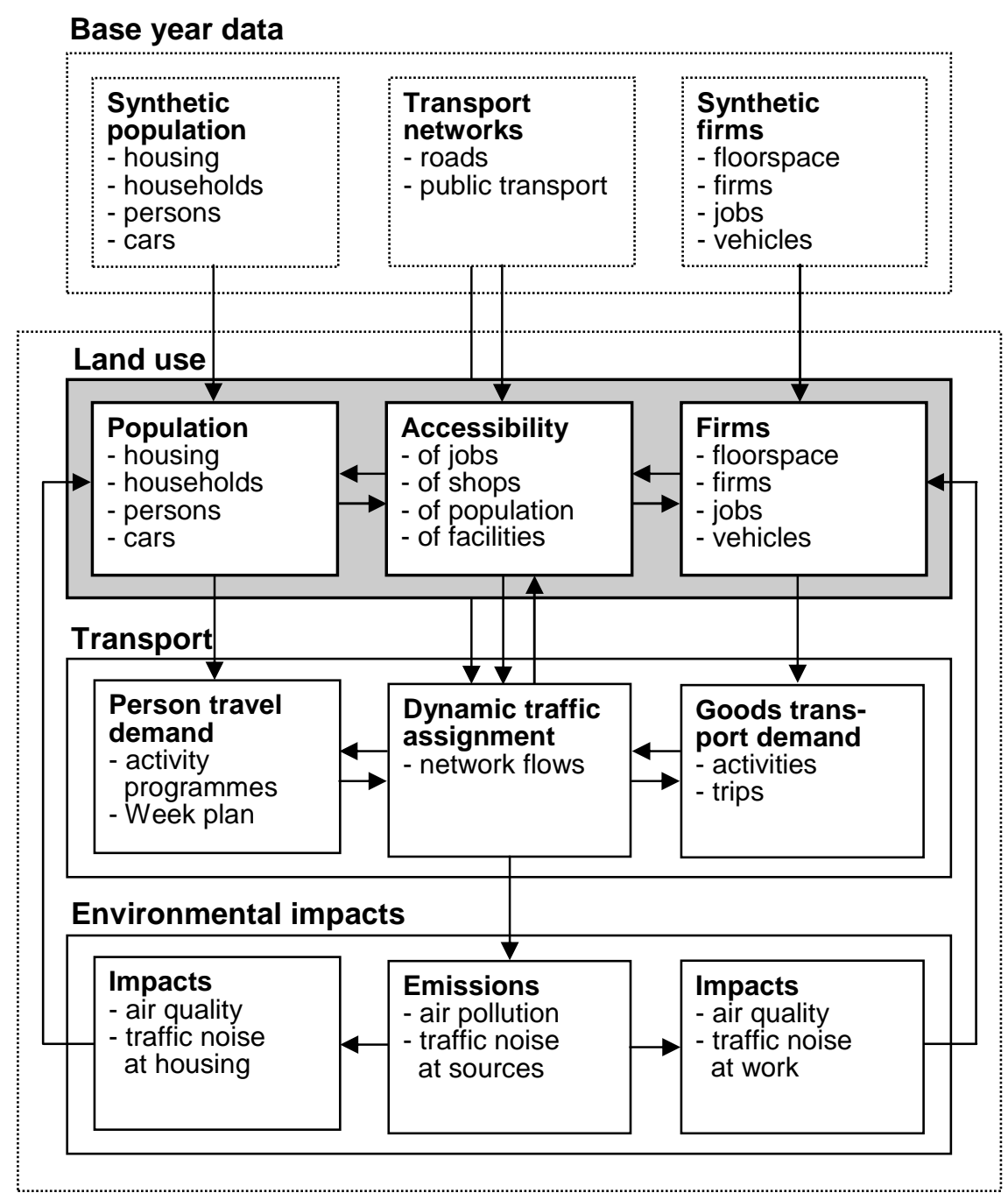

\section{ILUMASS model}

Figure 10 Integration of the land-use model into the ILUMASS model

The integrated model will be calibrated using data from household activity and travel surveys conducted in the study region and validated using aggregate time series data of population, housing and employment as well as data from traffic counts in the study region. The model will then be used to study the likely impacts of various policy alternatives in the fields of land-use and transport planning. Scenarios might cover land use planning alternatives, such as policies promoting high-density mixed-use inner-city development or policies fostering decentralised polycentric regional development, or transport infrastructure changes, such as new motorways or rail lines, or regulatory policies, such as area-wide speed limits, or monetary policies, such as road pricing, higher petrol taxes, or changes in rail fares or parking fees.

The definition of policy scenarios together with local planners will be a test of the policy relevance of the models. The results of the policy scenarios will contribute to the knowledge about feasible and successful policies and policy packages to achieve sustainable urban transport and may be used for finalising the new land-use plan and mobility master plan of the city of Dortmund. 


\section{The Future of Land-Use/Transport/Environment Models}

The ILUMASS model is completely disaggregate and deals with micro locations and movements of individual agents (households, firms and persons) and destinations on a surface of pixel-like grid cells combining a microscopic land-use model with a microscopic activity-based travel-demand model and a microscopic environmental impact model in one unified modelling framework. It remains to be asked whether the movement towards ultimate disaggregation in content, space and time is the right way to go.

From a technical point of view, the prospects are excellent. More powerful computers will remove former barriers to increasing the spatial, temporal and substantive resolution of models. The wealth of publicly available high-resolution spatial data will reduce aggregation errors in spatial models. Geographic information systems will become the mainstream data organisation of urban models. Spatial disaggregation of land-use and transport network data in raster GIS will permit the linkage between land-use transport models and dispersion (emission-immission) air-quality and noise-propagation models. Multiple representation of spatial data in raster and vector GIS will combine the advantages of spatial disaggregation (raster) and efficient network algorithms (vector). It will be possible to replace aggregate probabilistic approaches (e.g. entropy maximising) by disaggregate stochastic (microsimulation) approaches.

Miller et al. (1998) presented a matrix in which they charted the past and future evolution of urban land-use transport models. Figure 11 is an adaptation in which a sixth row L6 was added. The rows of the matrix correspond to different levels of modelling capability from pure travel models having no land-use model to activity-based land-use models using microsimulation. In a similar way, the columns of the matrix represent different levels of travel demand modelling capability from travel models considering only roads and auto travel to multimodal activity-based travel models using microsimulation.

Figure 11 Evolution of urban land-use transport models (adapted from Miller et al. 1998)

\begin{tabular}{|l|l|l|l|l|l|}
\hline \multicolumn{2}{|c|}{ Transport model } & T1 & T2 & T3 & T4 \\
\cline { 3 - 6 } & $\begin{array}{l}\text { No public } \\
\text { transport, no } \\
\text { modal split }\end{array}$ & $\begin{array}{l}\text { Public trans- } \\
\text { port, no logit, } \\
24 \mathrm{~h}\end{array}$ & $\begin{array}{l}\text { Public trans- } \\
\text { port, logit, } \\
\text { peak hour }\end{array}$ & $\begin{array}{l}\text { Multimodal, } \\
\text { activity-based }\end{array}$ \\
\hline L1 & None & & & & \\
\hline L2 & $\begin{array}{l}\text { Activity and } \\
\text { judgement }\end{array}$ & & & & \\
\hline L3 & $\begin{array}{l}\text { No market-based } \\
\text { land allocation }\end{array}$ & & & & \\
\hline L4 & $\begin{array}{l}\text { Logit allocation } \\
\text { with price signals }\end{array}$ & & & & \\
\hline L5 & $\begin{array}{l}\text { Market-based } \\
\text { land-use model }\end{array}$ & & & & \\
\hline L6 & $\begin{array}{l}\text { Activity-based } \\
\text { land-use model }\end{array}$ & & & & \\
\hline
\end{tabular}

Each cell of the matrix represents a land-use transport modelling combination, and the arrows 
indicate incremental paths of model evolution. The matrix could be made three-dimensional by adding the environment dimension which, as it has been shown, also provides strong reasons for making urban models more disaggregate. The question is what will happen with urban modelling when the lower right cell, the fully disaggregate activity-based model of land use, transport and the environment, as it is intended of the model presented in this paper, will have been reached.

There are voices in the ongoing debate about microsimulation in urban modelling suggesting that the lower right cell may not be the ultimate destination of model evolution. The price to be paid for all-out disaggregation in terms of data collection and computing effort may be too high for the level of generalisation at which the results could be of interest for policy making (Harris 2001). Disaggregate models may be suitable for modelling individual bottom-up behaviour but are incapable of taking account of larger macro trends which may arise from long-term socio-economic developments or from the interaction with other regions (Torrens 2001).

These considerations deserve careful attention. Their most likely consequence is that integrated urban models of the future will be multi-level in scope, space and time, i.e. model macro socio-economic trends at the level of the urban region at large (e.g. in multi-regional socio-economic models), meso developments at the level of urban districts or neighbourhoods (e.g. accessibility or attractiveness indicators) and individual behaviour at the micro, i.e. raster or parcel level. The challenge would be to capture the linkages between the levels in both downward and upward direction, i.e. to model how macro and meso developments influence micro behaviour and how individual behaviour accumulates to emergent patterns of collective behaviour.

\section{References}

Arentze T, Timmermans H (2000) ALBATROSS - A Learning Based Transportation Oriented Simulation System. European Institute of Retailing and Services Studies, Eindhoven.

Batty M (1994) A chronicle of scientific planning: the Anglo-American modeling experience. Journal of the American Planning Association 60: 7-16.

Domencich TA, McFadden D (1975) Urban Travel Demand. A Behavioral Analysis. Contributions to economic analysis 93. North-Holland Publishing Company, Amsterdam, Oxford.

Harris B (2001) The anatomy of microsimulation. Paper for the 7th International Conference on Computers in Urban Planning and Urban Management. University of Hawaii.

Landis J, Zhang M (1998a) The second generation of the California urban futures model. Part 1: Model logic and theory. Environment and Planning B: Planning and Design 25: 657-666.

Landis J, Zhang M (1998b) The second generation of the California urban futures model. Part 2: Specification and calibration results of the land use change module. Environment and Planning B: Planning and Design 25: 795-824.

Miller EJ (2001) Integrated Land Use, Transportation, Environment (ILUTE) Modelling System. <http://www.ilute.com/> [Accessed 5 July 2002]

Miller EJ, Kriger DS, Hunt JD, Badoe DA (1998) Integrated Urban Models for Simulation of Transit and Land use Policies. Final Report, TCRP Project H-12. Joint Program of Transportation, University of Toronto, Toronto.

Spiekermann K, Wegener M (1999) Disaggregate environmental modules for modelling sus- 
tainable urban development. In: Rizzi P (ed.) Computers in Urban Planning and Urban Management on the Edge of the Millennium. F. Angeli, Mailand.

Spiekermann K, Wegener M (2000) Freedom from the tyranny of zones: towards new GIS-based models. In: Fotheringham AS, Wegener M (eds.) Spatial Models and GIS: New Potential and New Models. GISDATA 7. Taylor \& Francis, London: 45-61.

Torrens PM (2001) Can geocomputation save urban simulation? Throw some agents into the mixture, simmer, and wait ... Working Paper 32. Centre for Advanced Spatial Analysis, University College London, London.

United States Environmental Protection Agency (2000) Projecting Land use Change. A Summary of the Effects of Community Growth and Change of Land use Patterns. Washington, DC.

Waddell P (2000) A behavioral simulation model for metropolitan policy analysis and planning: residential location and housing market components of UrbanSim. Environment and Planning B: Planning and Design 27: 247-263.

Wegener M (1994) Operational urban models: state of the art. Journal of the American Planning Association 60: 17-29.

Wegener M (1998) Applied models of urban land use, transport and environment: state-of-the-art and future developments. In: Lundqvist L, Mattsson L-G, Kim TJ (eds.) Network Infrastructure and the Urban Environment: Recent Advances in Land use/Transportation Modelling. Springer Verlag Berlin, Heidelberg, New York: 245-267.

Wegener M (1999) Die Stadt der kurzen Wege: Müssen wir unsere Städte umbauen? Berichte aus dem Institut für Raumplanung 43. Institut für Raumplanung, Dortmund.

Wegener M, Gnad F, Vannahme M (1986) The time Scale of Urban Change. In: Hutchinson B, Batty M (eds.) Advances in Urban Systems Modelling. North-Holland Amsterdam: 145-197. 